\title{
O FEMINICÍDIO ÍNTIMO E OS DESAFIOS EFETIVIDADE DA LEI MARIA DA PENHA: A DISCRICIONARIEDADE JUDICIAL E A CULTURA JURÍDICA DOS MAGISTRADOS DO TRATAMENTO DA VIOLÊNCIA DOMÉSTICA E FAMILIAR CONTRA A MULHER
}

\section{THE FEMICIDE AND THE CHALLENGES TO THE EFFECTIVENESS \\ OF THE LAW MARIA DA PENHA: JUDICIAL DISCRETION AND LEGAL CULTURE OF JUDGES IN THE TREATMENT OF DOMESTIC AND FAMILY VIOLENCE AGAINST WOMEN}

\footnotetext{
${ }^{1}$ Lilah de Morais Barrêto

${ }^{2}$ Federico Losurdo
}

\section{RESUMO}

Este artigo aborda o problema do feminicídio íntimo, destacando sua relação com o ciclo de violência doméstica e familiar contra a mulher. Identifica-se a negação ou subutilização dos institutos previstos na Lei Maria da Penha, em razão da cultura jurídica tradicional de tratamento da matéria sob a ótica privada e de aplicação do paradigma de justiça consensual a essa forma de violência. Serão analisados os acórdãos da Ação Declaratória de Constitucionalidade $n^{\circ}$. 19/DF e da Ação Direta de Inconstitucionalidade $n^{\circ}$. 4424/DF, bem como a resistência dos magistrados em observar o entendimento proferido nas referidas ações de controle concentrado de constitucionalidade.

PALAVRAS-CHAVE: Feminicídio; Lei Maria da Penha; Violência Doméstica e Familiar contra a Mulher; Discricionariedade Judicial

\begin{abstract}
This article discusses the problem of femicide, emphasizing its bond with the cycle of domestic violence against women. The denial and underuse of the institutes stated in the Law Maria da Penha is the consequence of a traditional legal culture that deals this problem as a private issue and faces this kind of violence with a consensual paradigm of justice. In this essay, we will analyze the judgments by the Brazilian Supreme Court in ADC $n^{\circ}$ 19/DF and $\mathrm{ADI} \mathrm{n}^{\circ} 4424 / \mathrm{DF}$, and the resistances of courts in following this settled jurisprudence.
\end{abstract}

KEYWORDS: Femicide;Maria da Penha Law; Domestic and Familiar Violence against Women; Judicial Discretion

\footnotetext{
${ }^{1}$ Mestranda do Programa de Pós-Graduação em Direito e Instituições do Sistema de Justiça da Universidade Federal do Maranhão - PPGDIR/UFMA, Maranhão, PI, (Brasil). E-mail: lilahbarreto@ yahoo.com.br.

${ }^{2}$ Phd. Professor Permanente do Programa de Pós-Graduação em Direito e Instituições do Sistema de Justiça da Universidade Federal do Maranhão - PPGDIR/UFMA Maranhão, PI, (Brasil). Habilitado na Itália como Professor Associado de Direito Constitucional. E-mail: federico.losurdo@uniurb.it.
} 


\section{INTRODUÇÃO}

O feminicídio, compreendido como o homicídio de mulheres em razão de condições de misoginia e desigualdades de gênero, manifesta-se como problema crônico e alarmante na sociedade brasileira, com dados que revelam a sua alta incidência e crescimento. $\mathrm{O}$ termo serve para visibilizar o caráter sexista desses crimes e desconstruir a aparente neutralidade que seu enquadramento como homicídio pode sugerir.

A Lei $\mathrm{n}^{\circ}$. 13.104/2015, com o intuito de atribuir tratamento penal mais rigoroso a esses crimes, altera o Código Penal para prever o feminicídio como uma das hipóteses de homicídio qualificado, bem como incluí-lo, por conseguinte, no rol de crimes hediondos. A lei em comento também define o que seria feminicídio, caracterizando-o como o homicídio praticado por razões da condição do sexo feminino da vítima. Considera-se, segundo os termos da lei, que o crime envolve essas razões nas seguintes circunstâncias: I - violência doméstica e familiar; e II - menosprezo ou discriminação à condição de mulher.

Esse diploma legal explicita uma realidade que também já se encontra publicizada nas pesquisas e estatísticas sobre a temática, nas quais resta demonstrado que a maior parte dos homicídios e agressões que vitimam as mulheres ocorrem no ambiente doméstico e familiar. Diante desse quadro e do ciclo da violência doméstica contra a mulher, que revela uma espiral crescente de agressões, uma análise sobre o feminicídio não pode prescindir de um estudo acerca da aplicação e efetividade dos institutos previstos na Lei Maria da Penha e de um enfoque sobre o feminicídio íntimo.

Este artigo objetiva analisar dois acórdãos do Supremo Tribunal Federal, proferidos na Ação Declaratória de Constitucionalidade $n^{\circ}$. 19/DF e na Ação Direta de Inconstitucionalidade $n^{\circ}$. 4424/DF, nos quais foi julgada a constitucionalidade da Lei Maria da Penha e de alguns de seus dispositivos. A perspectiva deste estudo será a de explorar a resistência de parcela do Judiciário brasileiro em reconhecer a criação de um microssistema específico para o tratamento da violência doméstica contra a mulher e a ruptura com o paradigma de justiça consensual, previsto na Lei $n^{\circ}$. 9099/95, afastada pela Lei Maria da Penha. Para tanto, serão observadas as concepções do direito de igualdade trazidas à baila nos votos dos ministros bem como o alcance dos direitos de proteção.

Serão questionados os limites das mudanças na legislação positiva ante a postura de discricionariedade judicial que nega efetividade ou subutiliza as disposições da Lei Maria da 
Penha, em manifesto apego à legislação anterior, a qual dispensava a esses conflitos tratamento sob a ótica privada e conciliatória. A ruptura com esse paradigma de justiça e, em última análise, com essa concepção do direito de igualdade e sua suposta colisão com os direitos de defesa e liberdade, é objeto de enfrentamento nesses dois acórdãos do Supremo Tribunal Federal.

Este estudo também visa problematizar a recalcitrância dos magistrados em negar aplicação aos preceitos da Lei Maria da Penha, mesmo após o Supremo Tribunal Federal ter firmado o entendimento pela sua constitucionalidade nos dois acórdãos em análise, o que se demonstra pela matéria presente em processos de Reclamação posteriores à sua publicação. Serão discutidos a discricionariedade judicial e o solipsismo dos magistrados que a informam, analisando sua relação com a efetividade dos diplomas legais abordados e a prática do feminicídio.

Adotou-se a metodologia de análise de conteúdo dos dois acórdãos do Supremo Tribunal Federal nas referidas ações de controle concentrado de constitucionalidade. Também foi realizada pesquisa jurisprudencial no sítio do Supremo Tribunal Federal na internet, utilizando como palavras chaves para busca "Lei Maria da Penha" e "Ação Pública Incondicionada", selecionando processos posteriores aos julgamentos da ADC no. 19/DF e ADIN n ${ }^{\circ} .4424 / \mathrm{DF}$, com o fim de analisar as controvérsias que persistem na jurisprudência em relação à matéria.

\section{FEMINICÍDIO: O DESFECHO FATAL DO CICLO DE VIOLÊNCIA CONTRA A MULHER}

\subsection{Violência Doméstica contra a Mulher e o Feminicídio: da necessária visibilização e enfrentamento de especificidades}

As expressões femicídio ou feminicídio referem-se aos assassinatos de mulheres por razões de gênero, ou seja, pela condição de mulher da vítima. Objetiva-se dar visibilidade ao caráter sexista desses crimes e à violência perpetrada contra as mulheres, tratando-os da perspectiva da desigualdade de gênero. A formulação do conceito femicide é atribuída à socióloga e feminista anglo-saxã Diana Russel, na década de 1970. 
Já a expressão femicídio íntimo foi introduzida em 1976, no Tribunal Internacional de Crimes contra Mulheres, sendo retomada, nos anos 90, para demonstrar a não acidentalidade das mortes violentas de mulheres, bem como o caráter sexista em crimes conjugais, sendo também caracterizado como uma política sexual de apropriação das mulheres (ALMEIDA, 1998).

Como explica Suely Almeida (1998), essa forma de violência contra a mulher, que ocorre no contexto doméstico e familiar, começou a ser objeto de tematização pública no Brasil através da mobilização de feministas e mulheres organizadas em diferentes movimentos, especialmente durante a década de 1980.

Nesse período, as primeiras campanhas de combate ao feminicídio, sob o lema "Quem ama não mata", passaram a ser divulgadas e integradas aos meios de comunicação. Foi também o momento de interpelação do poder público por esses movimentos, como a eficiente participação do movimento feminista no processo constituinte - o chamado lobby do batom, que resultou na incorporação de importantes reivindicações das mulheres brasileiras na Constituição Federal de 1988. Esse período foi marcado, destarte, por uma incipiente formação de uma agenda política feminista nacional, bem como pelas primeiras conquistas em termos de visibilidade dos problemas de desigualdade de gênero e criação de políticas públicas voltadas para a violência contra a mulher, a exemplo das Delegacias especializadas.

A ruptura com a invisibilidade e a naturalização das situações de violência contra a mulher, especialmente a doméstica e familiar, sempre encontrou como entrave a clássica dicotomia entre o público e o privado. A família e o ambiente doméstico são historicamente caracterizados como espaços despolitizados, nos quais deve prevalecer a intimidade e a preservação da entidade familiar como valores praticamente absolutos, obstaculizando a intervenção pública ou estatal para proteção à dignidade de seus membros (ROCHA, 2012).

Essa arraigada dicotomia na organização da sociedade assume feições de subalternização do feminino, ao mesmo tempo que reproduz e legitima a dominação sobre as mulheres. Conforme assinala Bourdieu (1999), é realizada uma divisão social baseada nas concepções de sexo e de identidades sexuais, elas próprias decorrentes da cultura e do trabalho histórico, inscrevendo-as em diversas instituições e estruturas da sociedade, como a família, a divisão sexual do trabalho, a divisão do trabalho sexual, o Estado, o modo de produção, a Igreja, o Direito, dentre outros, que ampliam e reproduzem esse modo de pensar e de percepção da realidade. 
Desta feita, observa-se que o gênero é constitutivo das relações sociais e, sendo culturalmente informado pela hierarquização e pela desigualdade, acarreta a violência. $\mathrm{O}$ gênero se apresenta como uma verdadeira gramática sexual, normatizando condutas masculinas e femininas. Na ordem falocrática e androcêntrica, reserva aos homens reconhecimento público, ao mesmo tempo que também lhes confere o monopólio do uso "legítimo" da força no espaço privado. Essas relações de poder, associadas ao muro de silêncio imposto pelo caráter de sacralidade concebido para a família, tornam o ambiente doméstico um espaço privilegiado de exercício de violência crônica, rotinizada, contra as mulheres (SAFFIOTI, 1995).

Foucault (2012) concebe as relações de poder como produtoras dos sujeitos e das individualidades, exercidas por dispositivos existentes em diferentes níveis da sociedade, em domínios e extensões variados, para os quais não há exterior possível. Assim, busca analisar em sua genealogia os poderes periféricos ou moleculares, com história e tecnologia próprias, que não representam mera extensão ou reprodução do poder do Estado, embora possam apresentar diferentes articulações com o aparelho estatal.

$\mathrm{Na}$ perspectiva foucaultiana, pode-se observar que os diversos dispositivos de poder que se espraiam na sociedade, nas diversas instituições, inclusive nas de âmbito privado, como a casa e a família - tradicionalmente encaradas como esfera de relações naturais e despolitizadas - produzem os sujeitos generificados, que demarcam posições e condutas a ser adotadas por homens e mulheres. Dentre esses dispositivos de poder, encontram-se as diversas formas de violência praticadas no ambiente doméstico e familiar, marcadas pela tensão entre o exercício de poderes e resistências.

Assim, as posições dos sujeitos nas relações de gênero extrapolam as posturas ou performances individuais, o indivíduo não seria a origem e a causa de suas práticas e de seu discurso. Butler (2013) propõe ainda uma crítica genealógica às categorias fundacionais de sexo, gênero e desejo, considerando as identidades como efeitos de instituições, práticas e discursos cujos pontos de origem são múltiplos e difusos. Seria uma análise que buscaria centrar-se e descentrar-se nas instituições do falocentrismo e da heterossexualidade compulsória.

Desta feita, a violência contra a mulher não pode ser vista como fenômeno casual, isolado, mas como prática permeada de regularidades, estabelecidas pela ordem de gênero, 
tanto na sua forma de exercício como dispositivo de poder e de controle social das mulheres, quanto na sua base de legitimação na sociedade e tolerância pelo Estado.

No tocante à violência doméstica e familiar contra a mulher, vários estudiosos apontam as regularidades da sua prática, verificando a presença de fases caracterizadoras de um ciclo de violência. Rocha (2007) esclarece que na primeira fase, denominada "tensão do homem/medo da mulher", o homem se utiliza de vários pretextos para justificar o desencadeamento da violência praticada. A autora prossegue explicando que, na segunda fase, denominada de "agressão do homem/cólera ou tristeza da mulher", ocorre o agravamento dos atos de violência, o que coloca em risco e compromete a integridade física e psicológica da mulher.

$\mathrm{Na}$ fase subsequente, o agressor tenta atribuir o seu comportamento a fatores externos, buscando minimizar a gravidade de seus atos e responsabilizar a vítima, por vezes acusando-a de dramatizar excessivamente a situação e de ter problemas mentais. Nessa terceira fase, denominada "desresponsabilização do homem/culpabilização da mulher", a vítima internaliza a culpa pela violência sofrida e tenta afastá-la mudando o próprio comportamento.

Rocha (2007) assinala que na última fase, chamada de "perdão do homem/esperança da mulher" ou "lua-de-mel", a violência cessa, há os pedidos de ajuda e desculpas, as promessas por parte do agressor, a oferta de presentes, a reconciliação. A mulher renova suas esperanças na mudança de comportamento do agressor, haja vista que ele se mostra amável e calmo nessa fase, e resolve manter a relação. Ocorre que, depois de algum tempo, o ciclo recomeça, e a lembrança dessa fase dificulta que a vítima perceba que os novos episódios de violência constituem parte desse círculo.

A descrição desse ciclo demonstra as ambivalências, resistências, recuos, imbricados nas situações de violência no contexto de relações de afeto e familiares. As especificidades desses conflitos que, ao mesmo tempo, refletem e reproduzem as identidades de gênero dominantes - nas quais mulheres são identificadas pelas virtudes do perdão, da passividade, do sacrifício pessoal em prol da família, da conciliação - dificultam a ruptura com a violência, bem como representam o solapamento da relativa autonomia da mulher.

A manifestação da violência doméstica e familiar contra a mulher de forma cíclica é acompanhada de uma escalada nas agressões, que podem culminar com o feminicídio, mormente quando não ocorre a judicialização do conflito ou quando este é judicializado sem 
que o aparato policial-judiciário considere as relações de desigualdade e desequilíbrio entre as partes, redundando em desistências da vítima em prosseguir com os processos, na completa falta de garantia de sua segurança e em impunidade do agressor.

\subsection{A Lei Maria da Penha e a Lei do Feminicídio: possibilidades e limites da legislação protetiva e repressiva}

Deve-se reconhecer que o feminicídio não é praticado somente no âmbito doméstico e familiar, ele também se apresenta em outros espaços, embora sempre orientado por uma lógica misógina de apropriação da mulher e sua objetificação. Em muitos casos, o assassinato é acompanhado de violência sexual, mutilações e tortura, motivados pelo sentimento de ódio, desprezo e posse sobre as mulheres.

No entanto, avulta a importância de fazer uma abordagem direcionada ao feminicídio íntimo, por sua alta incidência e por ser caracterizado por uma espiral crescente e rotinizada de violência, apresentando-se num contexto de mortes anunciadas, porém que ainda não encontram enfrentamento adequado por parte do Poder Público para sua prevenção. Esta alarmante e crônica realidade está demonstrada em pesquisas e estatísticas realizadas no Brasil, que despertam a atenção dos movimentos feministas e das organizações internacionais de Direitos Humanos, a exemplo dos que se seguem.

Segundo o balanço dos atendimentos realizados em 2014 pela Central de Atendimento à Mulher - Ligue 180, da Secretaria de Políticas para as Mulheres da Presidência da República (SPM-PR), 43\% das mulheres em situação de violência sofrem agressões diariamente; para 35\%, a agressão é semanal (COMPROMISSO E ATITUDE, 2015). A última pesquisa DataSenado revela que uma em cada cinco mulheres já foi espancada pelo marido, companheiro, namorado ou ex. (SENADO FEDERAL, 2015).

Acerca dos feminicídios, o Mapa da Violência 2015 aponta que, entre 2003 e 2013, o número de vítimas do sexo feminino passou de 3.937 para 4.762 , incremento de $21,0 \%$ na década. Essas 4.762 mortes em 2013 representam 13 homicídios femininos diários. Com uma taxa de 4,8 assassinatos em 100 mil mulheres, o Brasil está entre os países com maior índice de homicídios femininos: ocupa a quinta posição em um ranking de 83 nações (WAISELFISZ, 2015). 
Os levantamentos realizados demonstram que o feminicídio apresenta-se como um problema crônico e arraigado na sociedade brasileira, bem como sua intrínseca relação com a violência praticada no ambiente doméstico e familiar. Em razão desse quadro alarmante, foi editada legislação específica, a Lei Maria da Penha, resultante de pressão dos movimentos de mulheres e organismos internacionais de direitos humanos.

Impende registrar que a edição da Lei Maria da Penha também foi resultado de recomendações feitas ao Brasil pelo Comitê sobre a Eliminação da Discriminação contra a Mulher das Nações Unidas (Comitê CEDAW) e pela Comissão Interamericana de Direitos Humanos da Organização dos Estados Americanos - OEA. No caso do Comitê CEDAW, em resposta ao Relatório Nacional brasileiro de 2002, foram apontadas como principais preocupações para efetividade da Convenção "a persistente violência contra mulheres e meninas", a indulgência com que são punidos seus agressores, a insuficiente abordagem sobre a violência contra a mulher, em razão da falta de informações e de dados e a inexistência de uma lei sobre violência doméstica. Em relação à OEA, cumpre registrar a condenação do Estado brasileiro por negligência e omissão em relação ao caso da vítima Maria da Penha Maia Fernandes (ROCHA, 2012).

A Lei Maria da Penha prevê um microssistema para o atendimento mais célere, integrado e especializado da mulher vítima de violência doméstica e familiar. Em atenção ao caráter multifacetado e complexo dessa forma de violência, o diploma legal em comento previu a instituição de Juizados de Violência Doméstica e Familiar contra a Mulher (JVDFMs), com competência cível e criminal para o processo, o julgamento e a execução das causas decorrentes da prática de violência doméstica e familiar contra a mulher.

Outra inovação foi o instituto das medidas protetivas de urgência, de natureza cautelar, com a finalidade de garantir proteção e assistência às vítimas. Esse novo instituto visa evitar uma visão fracionada do problema, atentando para inquietações comuns entre as vítimas, como alimentos, guarda dos filhos menores, proximidade com o agressor após a denúncia, moradia no lar do casal, dentre outras. Observou-se, destarte, repercussões cíveis, familiares e de segurança da ofendida, que costumam levá-la ao silenciamento e cristalizam as situações de violência (DIAS, 2007).

No entanto, são necessários muitos avanços para a aplicação da Lei Maria da Penha em sua integralidade. No que tange à insuficiência das políticas públicas previstas na lei, tanto a ausência de uma rede integrada aos JVDFMs para acompanhamento do cumprimento das 
medidas protetivas de urgência e garantia de sua efetividade, quanto o fato desses Juizados não terem sido instalados na maioria das comarcas do país, ainda comprometem a consecução das finalidades propostas na norma em apreço. (AZEVEDO; CRAIDY, 2011).

Para além das dificuldades estruturais, verificam-se obstáculos relacionados à cultura social e jurídica dos agentes das instituições do sistema de justiça brasileiras, incluindo os membros da magistratura, bem como de deficiências na formação desses profissionais para enfrentamento das especificidades da violência doméstica e familiar contra a mulher.

A Lei Maria da Penha optou por romper com a tradição jurídica de subalternização do conflito doméstico, de cisão entre espaços público e privado, que imputava toda a responsabilidade pela solução do litígio à vítima pressionada e fragilizada psicologicamente. Hermann e Barsted (1995) apontam a histórica banalização desses crimes, ressaltando que a seletividade punitiva opera de modo a tratar os assim chamados crimes domésticos como uma espécie de conflito de "segunda divisão". As autoras consideram que tal discriminação reforça as assimetrias entre os gêneros, haja vista que as mulheres predominam entre as vítimas dos crimes cometidos no espaço privado.

O paradigma de justiça consensual encontrou sua maior expressão no sistema da Lei nº 9099/95, apontado pelo Relatório Nacional Brasileiro ao Comitê para a Eliminação de Todas as Formas de Discriminação contra a Mulher das Nações Unidas como fator de banalização dessa forma específica de violência, haja vista que era aplicado à maioria desses crimes e contava com inúmeros institutos despenalizadores.

Se por um lado, teoricamente, a lei que criou os Juizados Especiais Criminais apresenta rápida solução para o conflito, sendo apontada por alguns como avanço em termos de Direito Penal, por outro ela desconsidera a desigualdade de poder presente nos casos de violência doméstica e acabava representando um estímulo para a desistência das vítimas em processar seus agressores e reforçando a impunidade (BARSTED, 2007).

Rocha (2007a) aborda os aspectos negativos do induzimento à conciliação e do estímulo à renúncia do direito de representação da vítima em relações desiguais. Citando Campos (2003), assinala que tal procedimento reprivatiza o conflito, de modo que o juiz, abdicando da função de equalizar a relação desigual entre as partes, devolve à vítima a solução do conflito, o que redistribui o poder da relação em favor do réu.

A condução e mediação desses conflitos sob a ótica privada reflete a cultura jurídica tradicional acerca da violência doméstica e familiar contra a mulher. Assim, apesar de a Lei 
Maria da Penha ter afastado expressamente a aplicação das disposições da Lei nº 9099/95 (artigo 41), seus institutos despenalizadores continuaram a ser empregados na jurisprudência dos tribunais pátrios.

O problema da discricionariedade dos agentes das instituições do sistema de justiça para negar aplicação às disposições legais nos casos que envolvem essa forma de violência é bem anterior à Lei Maria da Penha e à própria Lei $n^{\circ}$. 9099/95, representam uma tradição institucional de decisionismo e subjetivismo dos profissionais do Direito, mormente em crimes considerados historicamente como de menor importância.

Em análise realizada antes da edição das aludidas leis, mas que permanece bastante atual, Almeida (1998) explica que o aparato policial-judiciário desrespeita a lei e busca legitimar sua omissão nas representações quanto à participação da mulher nessa forma de conflito. Essa participação é representada sob a forma de culpabilização da mulher, seja pelo fracasso na gestão familiar que lhe é atribuído, seja pela incapacidade, que também lhe é imputada, de interromper de imediato a relação violenta, seja também por sua fragilidade para perseguir o processo jurídico.

No tocante à opção feita pelo legislador na Lei Maria da Penha de ruptura com o sistema previsto na Lei $\mathrm{n}^{\circ}$. 9099/95, verifica-se ferrenha resistência. Conforme apontam Azevedo e Craidy (2011), a renúncia à representação da vítima nos crimes de lesões corporais leves e a suspensão condicional do processo continuaram sendo admitidas em diversos acórdãos de diferentes tribunais - a exemplo do TJRS, TJSP, TJRJ e o TJMG - sem que houvesse entendimento pacificado, gerando profundas controvérsias quanto à sua aplicação.

Essas controvérsias geraram a necessidade de que o Supremo Tribunal Federal se pronunciasse sobre a matéria, o que foi levado a efeito na Ação Declaratória de Constitucionalidade $n^{\circ}$ 19/DF e na Ação Direta de Inconstitucionalidade $n^{\circ}$. 4.424/DF, que serão analisadas a seguir.

\section{CONTROVÉRSIAS SOBRE A CONSTITUCIONALIDADE DA LEI MARIA DA PENHA}

\subsection{A Ação Declaratória de Constitucionalidade $n^{\circ}$. 19/DF}

A Presidência da República propôs a Ação Declaratória de Constitucionalidade $\mathrm{n}^{\circ}$. 19/DF, com o objetivo de que fossem declarados constitucionais os artigos $1^{\circ}, 33$ e 41 da Lei Maria da Penha. Habilitaram-se como Amici curiae as seguintes entidades: Conselho Federal 
da Ordem dos Advogados do Brasil, Assessoria Jurídica e Estudos de Gênero - THEMIS, Instituto para a Promoção da Equidade - IPÊ, Instituto Antígona -organizações integrantes e representantes do Comitê Latino Americano e do Caribe para a Defesa dos Direitos da Mulher - CLADEM/Brasil e Instituto Brasileiro do Direito de Família - IBDFAM. Obteve parecer favorável da Procuradoria Geral da República. O acórdão foi da relatoria do Ministro Marco Aurélio e a ação julgada procedente por unanimidade.

O artigo $1^{\mathrm{o}}$ da Lei Maria da Penha foi objeto da presente demanda em razão de decisões judiciais que negaram aplicação ao referido diploma legal, por considerarem que o estabelecimento de tratamento diferenciado à violência doméstica e familiar contra a mulher estaria violando o princípio da igualdade.

O artigo 33 também foi alvo de controvérsias, por haver entendimentos de que a previsão de que fossem criados os Juizados de Violência Doméstica e Familiar contra a Mulher e a atribuição das competências cível e criminal relativas à violência doméstica e familiar contra a mulher às Varas Criminais, enquanto esses Juizados não fossem criados, implicariam usurpação da competência normativa dos estados quanto à própria organização judiciária.

Também foram apresentados vários posicionamentos jurisprudenciais divergentes sobre a constitucionalidade do artigo 41, o qual afasta a aplicação da Lei nº 9099/95 para os crimes de violência doméstica e familiar contra a mulher.

O Ministro Marco Aurélio, relator do processo, fundamenta seu posicionamento a favor da constitucionalidade das disposições da Lei Maria da Penha da seguinte forma: afirma que a lei em apreço confere concretude ao artigo 226, § $8^{\circ}$, da Constituição Federal; que a competência dos Juizados Especiais Criminais para julgamento dos crimes de menor potencial ofensivo, prevista no artigo 98, I, da CF, depende do que a lei definir, em sua opção políticonormativa, como pertencente a esse rol; na concepção de igualdade material ou real, para a qual representaria uma afronta "tratar desiguais com igualdade"; na vulnerabilidade da mulher e sua histórica discriminação e sujeição no âmbito privado; nos Tratados Internacionais nos quais o Brasil é parte; no princípio da proibição da proteção insuficiente dos direitos fundamentais; na existência de outros microssistemas de proteção, como o Estatuto da Criança e do Adolescente e Estatuto do Idoso; no fato de que a lei estabelece uma faculdade de criação dos Juizados; e na prerrogativa da União de estabelecer regras sobre o processo. 
A Ministra Rosa Weber, o Ministro Luis Fux, o Ministro Dias Toffoli, a Ministra Carmen Lúcia, o Ministro Ricardo Lewandowski, o Ministro Ayres Brito, o Ministro Gilmar Mendes, o Ministro Celso de Mello e o Ministro Cezar Peluso acompanharam o voto do relator, reproduzindo, em grande medida, fundamentos do mesmo jaez.

Pode-se considerar que os núcleos de sentido dos votos proferidos na ADC nº. 19/DF referem-se fundamentalmente ao embate entre concepções distintas do princípio da igualdade. O cerne da discussão sobre os dispositivos da Lei Maria da Penha em exame é o tratamento diferenciado para a violência doméstica e familiar contra a mulher, seja quando se questiona a própria edição de uma legislação específica, seja quando se reafirma a competência dos Juizados Especiais Criminais, ou ainda quando se continua aplicando os institutos despenalizadores da Lei $n^{\circ}$. 9099/95.

A compreensão do microssistema previsto na lei em apreço como conforme ao princípio constitucional da igualdade dependerá de uma ruptura e reformulação de conceitos clássicos e liberais, a exemplo do absenteísmo estatal como suficiente à efetivação dos direitos fundamentais; o de igualdade jurídica, assentada em critérios formais; o de soberania dos Estados, considerada como absoluta e inacessível a qualquer controle internacional; bem como o de cisão entre espaços público e privado, que mantinham o ambiente doméstico e familiar como insuscetível de intervenção pelo Poder Público por ser espaço privilegiado de defesa do indivíduo contra o Estado.

A perspectiva material do direito à igualdade e essa mudança de paradigmas se caracteriza pela especificação do sujeito de direitos. Esse processo parte da necessidade de considerar o indivíduo concreto, com suas especificidades e historicamente situado, gerando sistemas especiais de proteção de Direitos Humanos e sua incorporação na ordem jurídica interna dos Estados, através de medidas compensatórias, as chamadas ações afirmativas, em favor de grupos historicamente mais vulneráveis (PIOVESAN, 2003).

Em se tratando de situações de vulnerabilidade de determinados sujeitos nas relações privadas, faz-se mister abordar a eficácia horizontal dos direitos fundamentais e os consequentes deveres de proteção do Estado. Sarlet (2009) reconhece, como ponto de partida para o reconhecimento de uma eficácia dos direitos fundamentais na esfera das relações privadas, a constatação de que, ao contrário da concepção do Estado clássico e liberal de Direito, a liberdade individual não apenas carece de proteção contra os Poderes públicos, mas também contra os mais fortes no âmbito da sociedade. O autor salienta, outrossim, a 
perspectiva jurídico-objetiva dos direitos fundamentais, que vinculam o legislador no sentido positivo, ou seja, vinculam o legislador a deveres ativos de proteção, bem como a um dever de aperfeiçoamento da legislação existente, no sentido de conformação da ordem jurídica a seus preceitos.

\subsection{A Ação Direta de Inconstitucionalidade $n^{0}$. 4424/DF}

A Procuradoria-Geral da República (PGR) ajuizou a Ação Direta de Inconstitucionalidade $\mathrm{n}^{\circ}$. 4424/DF, com o objetivo de dar interpretação conforme à Constituição aos artigos 12, inciso I, 16 e 41 da Lei Maria da Penha. Para declarar a inaplicabilidade da Lei $\mathrm{n}^{\circ}$ 9.099/95 aos crimes versados naquele diploma, assentar, como consequência, que o crime de lesão corporal leve praticado contra a mulher em ambiente doméstico é processado mediante ação penal pública incondicionada e restringir a aplicação dos artigos 12, inciso I, e 16 da norma em comento às ações penais cujos crimes estejam previstos em leis diversas da Lei $\mathrm{n}^{\circ} 9.099$, de 1995.

A ADIN em comento foi julgada na mesma data que a ADC nº 19/DF, qual seja, no dia 09 de fevereiro de 2012. O Supremo Tribunal Federal julgou a ADIN procedente, por maioria de votos, determinando o processamento dos crimes de lesão corporal abrangidos pela Lei Maria da Penha, independentemente de sua gravidade, por Ação Penal Pública Incondicionada, nos termos do voto do relator, tendo como único voto divergente o voto do Ministro Cezar Peluzo. Segue uma síntese dos votos de cada Ministro.

O relator do processo, o Ministro Marco Aurélio, apresentou as seguintes razões para votar a favor da procedência da ação: a renúncia à representação pela vítima na imensa maioria dos casos de lesão corporal leve e o fato desta renúncia não possuir natureza de manifestação livre e espontânea; a espontaneidade da manifestação de vontade é cerceada pelo temor, pela pressão psicológica e econômica, pelas ameaças sofridas, bem como pela assimetria de poder decorrente de relações histórico-culturais, pelos graves impactos emocionais impostos pela violência de gênero à vítima, o que a impede de romper com o estado de submissão; a retratação da vítima leva à reiteração da violência de forma cada vez mais agressiva, de forma a desaguar, em muitos casos, em seu assassinato; a maior parte da violência perpetrada contra a mulher ocorre dentro de casa, no âmbito de relações privadas e invisibilizadas, bem como os assassinatos são praticados, em sua maioria, por homens com 
quem as vítimas mantêm ou mantiveram relacionamentos amorosos; as lesões corporais leves e culposas decorrentes de violência doméstica e familiar contra a mulher ensejam tratamento normativo desigual em relação aos crimes de lesão corporal em geral; o condicionamento da atuação do Estado e do Ministério Público à representação da vítima contribui para a diminuição de sua proteção, para a prorrogação da situação de violência, discriminação e ofensa à dignidade humana; a Lei Maria da Penha não pode ser interpretada de forma dissociada do Diploma Maior e dos tratados de direitos humanos ratificados pelo Brasil; a especificação dos sujeitos de direito legitima as discriminações positivas; a dignidade da pessoa humana (artigo $1^{\circ}$, inciso III, da CF); o direito fundamental de igualdade (artigo $5^{\circ}$, inciso I, da CF); a previsão pedagógica segundo a qual a lei punirá qualquer discriminação atentatória dos direitos e liberdades fundamentais (artigo $5^{\circ}$, inciso XLI, da CF); o dever do Estado de assegurar a assistência à família na pessoa de cada um dos que a integram, criando mecanismos para coibir a violência no âmbito de suas relações (artigo 226, § $8^{\circ}$, da CF); o histórico da Lei Maria da Penha, mediante o Informe $\mathrm{n}^{\circ}$. 54/2001, da Comissão Interamericana de Direitos Humanos da Organização dos Estados Americanos; a Convenção sobre a Eliminação de Todas as Formas de Violência contra a Mulher; a Convenção Interamericana para Prevenir, Punir e Erradicar a Violência contra a Mulher - a Convenção de Belém do Pará; o julgamento do Habeas Corpus $n^{\circ}$ 106.212/MS, no qual se declarou a constitucionalidade do artigo 41 da Lei Maria da Penha, que afasta a aplicação da Lei ${ }^{\circ}$. 9099/95 para os crimes de violência doméstica e familiar contra a mulher.

Esse foi o voto condutor, seguido pela maioria dos Ministros, que também apresentaram fundamentação convergente nesta mesma esteira interpretativa. Acompanharam o relator os Ministros: Ministros Celso de Mello, Marco Aurélio, Gilmar Mendes, Ayres Britto, Joaquim Barbosa, Ricardo Lewandowski, Cármen Lúcia, Dias Toffoli, Luiz Fux e Rosa Weber.

O voto divergente foi do Ministro Cezar Peluso, cujos fundamentos para julgar a ADIN improcedente, mantendo a ação pública condicionada à representação para os crimes de lesão corporal leve em sede de violência doméstica e familiar contra a mulher, foram os seguintes: as mulheres se sentirão intimidadas para levar às autoridades o conhecimento do crime porque não poderão interromper o andamento da Ação Penal; caso haja reconciliação com o parceiro agressor, a família sofrerá com sua eventual condenação; a impossibilidade de intervenção da mulher pode fazer com que ela sofra represálias violentas; compatibilização 
entre valores constitucionais da proteção da condição da mulher e a necessidade da manutenção da situação familiar; respeito à dignidade da pessoa humana através da liberdade de escolha de cada indivíduo sobre seu próprio destino; estudos de algumas associações, entre elas a "Defesa de Gênero", o "Coletivo Feminista de São Paulo", o "Instituto Noos" (que atua na prevenção e cessação da violência intrafamiliar e de gênero), o IPEA (Instituto de Pesquisa Econômica Aplicada), demonstrando "eventual conveniência de se manter o procedimento da Lei 9099/05", notadamente quanto às suas características de celeridade e oralidade.

Cumpre registrar o teor do voto do Ministro Gilmar Mendes que, apesar de acompanhar o relator, não apresentou fundamentos para este entendimento. Apenas ressalvou que a própria ação penal pública incondicionada vai ser um elemento de tensão familiar e, eventualmente, de desagregação familiar. No entanto, alegando não dispor de dados para manter a ação pública condicionada à representação e seguir no sentido contrário ao relator e demais Ministros que lhe antecederam o voto, acompanhou o voto do relator.

Observa-se que, no julgamento da ADIN, continua em debate, embora não o seja de forma explícita, a consecução do princípio de igualdade em sua acepção material. Deveras, trata-se da escolha entre preconizar os direitos de proteção à mulher vítima de violência doméstica e familiar e a compensação da desigualdade entre agressor e vítima, de um lado; ou, por outro lado, privilegiar a defesa da suposta autonomia dessa vítima em relação ao Estado, desconsiderando a sua vulnerabilidade nas relações privadas, bem como priorizar a manutenção da entidade familiar, preservando o paradigma de não interferência - ou interferência mínima - do Estado no âmbito das relações familiares, ainda que em situação de violência e afronta à dignidade da mulher.

Haberle (2005) esclarece acerca da dupla direção protetiva da dignidade humana, devendo ser cumprida pelo Estado de maneira clássica, ou seja defensivamente, mas também de forma prestacional, de modo a proteger o indivíduo contra terceiros. Nessa última dimensão, a cláusula da dignidade humana se apresenta como um encargo constitucional endereçado ao Estado, que pode realizá-lo por caminhos jurídico-materiais e por vias processuais (no sentido de um status activus processualis), bem como por meios ideiais e materiais.

No que tange especificamente à aplicação dos institutos despenalizadores previstos na Lei $n^{\circ} .9099 / 95$ aos casos de violência doméstica e familiar contra a mulher e de como tal interpretação acarreta a equiparação de desiguais, em dissonância com a concepção material 
de igualdade, Campos e Carvalho (2006) assinalam que a composição civil, não obstante ser usualmente encarada como momento privilegiado para a vítima, pressupõe dois litigantes em igualdade de condições. Os autores ressaltam que esse sistema foi pensado para os conflitos entre figuras como Caio e Tício, em disputa eventual e isolada, e não para conflitos entre sujeitos como Tício e Joana, que apresentam um histórico de relação afetiva e violência rotinizada, bem como encontram-se envolvidos em relações de profunda assimetria de poder.

\section{A DISCRICIONARIEDADE JUDICIAL E A NEGAÇÃO À EFETIVIDADE DA LEI MARIA DA PENHA}

Conforme analisado ao longo deste estudo, parcela do Judiciário apresenta profunda resistência para dar aplicação às disposições da Lei Maria da Penha, o que subutiliza os seus institutos e mantém intacto o paradigma de justiça consensual e o tratamento do conflito sob a ótica privada, corolários do sistema jurídico previsto na Lei nº. 9099/95.

O apego aos institutos da legislação anterior, expressamente afastados para os crimes de violência doméstica e familiar contra a mulher, tanto pela literalidade do texto da Lei Maria da Penha, quanto pelo teor dos acórdãos do Supremo Tribunal Federal que o confirmaram em sede de controle concentrado de constitucionalidade, justifica-se pelo despreparo dos membros das instituições de justiça para lidar com as especificidades dessa forma de violência e das relações desiguais de gênero, mantendo uma postura discricionária e de subversão do texto legal.

Nesse sentido, Campos e Carvalho (2006) alertam que a cultura decisionista, empregada na condução dos processos de violência doméstica e familiar contra a mulher nos termos do microssistema dos Juizados Especiais Criminais, re-privatiza o conflito, de modo que novas violências conjugais não são prevenidas e novas violências públicas (do processo) são acrescentadas ao desgastado relacionamento.

Exemplos claros de subversão do texto legal, em afronta à disciplina da matéria definida pelas vias democráticas da legislação e já submetida à sindicabilidade constitucional, por quem possui a competência precípua para fazê-lo de forma definitiva em nossa ordem jurídica, qual seja, o Supremo Tribunal Federal, encontram-se nas negativas de dar aplicação aos dispositivos da Lei Maria da Penha, preservando, por discricionariedade do julgador, o regramento de lei expressamente afastada. Luiz (2013) adverte sobre os riscos de se admitir o 
solipsismo interpretativo, ressaltando que, em uma democracia, não se pode depender da consciência de uma pessoa ou julgador em detrimento do pacto social fundante (a Constituição).

Foi realizada pesquisa de acórdãos através de mecanismo de busca no sítio do Supremo Tribunal Federal na internet, utilizando como palavras chaves para busca "Lei Maria da Penha" e "Ação Pública Incondicionada", selecionando os processos posteriores aos julgamentos da ADC no. 19/DF e ADIN nº 4424/DF. Foram encontradas diversas Reclamações, julgadas procedentes, em que se reafirma a natureza de ação penal pública incondicionada para os crimes de lesão corporal leve albergados na disciplina da Lei Maria da Penha, cassando as decisões que descumprem o disposto nos acórdãos das referidas ações de controle concentrado de constitucionalidade e extinguem a punibilidade em razão de retratação da vítima.

Seguem alguns exemplos, a título ilustrativo: Rcl 18565, Relator(a): Min. LUIZ FUX, julgado em 10/02/2016, publicado em PROCESSO ELETRÔNICO DJe-027 DIVULG 12/02/2016 PUBLIC 15/02/2016; Rcl 20448, Relator(a): Min. DIAS TOFFOLI, julgado em 07/10/2015, publicado em PROCESSO ELETRÔNICO DJe-204 DIVULG 09/10/2015 PUBLIC 13/10/2015; Rcl 17715, Relator(a): Min. MARCO AURÉLIO, julgado em 03/08/2015, publicado em PROCESSO ELETRÔNICO DJe-159 DIVULG 13/08/2015 PUBLIC 14/08/2015.

Verifica-se pelas datas de julgamentos de várias reclamações, bastante recentes, que ainda persistem as resistências de parcela dos membros da magistratura em dar cumprimento aos preceitos da Lei Maria da Penha e acolher a pretensão punitiva em relação aos crimes de violência doméstica e familiar contra a mulher, inclusive em desacordo ao entendimento já firmado pelo Supremo Tribunal Federal no âmbito do controle concentrado de constitucionalidade, permanecendo hodierno o tratamento controvertido da matéria e a consequente insegurança jurídica.

Nesse aspecto, merece destaque o posicionamento adotado pelo Superior Tribunal de Justiça que, solucionando divergência entre suas Turmas em Recurso Especial Representativo da Controvérsia nº 1.097.042/DF, posterior ao julgamento da ADC nº 19/DF e ADIN nº. 4424/ DF, firma entendimento oposto ao fixado pelo Supremo Tribunal Federal nas aludidas ações de controle concentrado. Os julgados do STJ também foram questionados no STF, através de Recurso Extraordinário, a exemplo do RE 826760, Relator(a): Min. TEORI 
ZAVASCKI, julgado em 01/08/2014, ao qual o Supremo Tribunal Federal deu provimento, mantendo o entendimento sedimentado nas ações de controle concentrado de constitucionalidade.

Percebe-se que o solipsismo, ou as decisões conforme a consciência dos julgadores que afastam as disposições legais - nos mantém em constante estado de insegurança jurídica, a depender da opinião pessoal de juízes e promotores sobre as leis (STRECK, 2013). Essa insegurança jurídica é sobremodo prejudicial a grupos mais vulneráveis e carecedores de proteção do Estado, como é o caso das mulheres vítimas de violência doméstica e familiar. Destarte, a negação da nova disciplina estabelecida pela Lei Maria da Penha, com a persistência do emprego dos institutos despenalizadores que foram expressamente afastados, preservam o caráter seletivo do nosso Direito Penal, em desfavor da publicização desses crimes e do combate à sua impunidade.

\section{5. À GUISA DE CONCLUSÃO}

O feminicídio e a violência contra a mulher representam as expressões mais dramáticas e fatais de um problema mais amplo, a violência de gênero, que mobiliza diversos dispositivos de poder espraiados na sociedade para estabelecer padrões de hierarquização entre os sexos e de subalternização do feminino, bem como uma política de controle social das mulheres. Desta feita, torna-se imprescindível promover a visibilidade do problema, através de tipificações e demais instrumentos legais e institucionais específicos, que demonstrem o caráter sexista desses crimes, tirando-os da aparente neutralidade da classificação genérica como homicídios, crimes conjugais ou passionais, ou simples violência urbana.

Optou-se neste estudo por dar maior ênfase ao feminicídio íntimo, praticado no contexto de violência doméstica e familiar, por considerá-la como resultante de uma espiral crescente de atos violentos, o que as caracteriza como mortes anunciadas. Sua dimensão política é omitida, especialmente quanto à tolerância estatal e sua banalização, haja vista que o aparato policial-judiciário reprivatiza o conflito e preserva o caráter de sacralidade do espaço familiar em detrimento da dignidade da mulher.

A arraigada tradição jurídica de cisão entre os espaços público e privado, ignorandose os deveres de proteção estatal para garantia da eficácia dos direitos fundamentais entre 
particulares, é uma opção política do Estado, que contribui para que se reproduzam as desigualdades nas relações de gênero e sejam produzidas novas formas de violência em âmbito institucional. Como o Estado não é uma instituição monolítica, existem iniciativas legislativas, como a Lei Maria da Penha, que visam uma ruptura com esse paradigma de justiça consensual e de absenteísmo do Poder Público, caracterizando a violência doméstica e familiar contra a mulher como grave violação aos direitos humanos e não como simples querela de cunho privado.

Ocorre que, mesmo após a edição do referido diploma legal, continua sendo negada aplicação a seus dispositivos, bem como são subutilizados seus institutos, em manifesto apego ao sistema jurídico anterior e mediante prática de discricionariedade judicial, sendo proferidas decisões que demonstram a resistência de parcela do Judiciário brasileiro à mudança de paradigmas propugnada pela Lei Maria da Penha.

A jurisprudência nesse sentido gerou a necessidade de provocação do Supremo Tribunal Federal para que se pronunciasse acerca da constitucionalidade da lei em comento e pusesse fim às controvérsias sobre sua aplicação. Após o julgamento, no qual foram declaradas constitucionais as inovações trazidas na legislação específica e fixados os parâmetros para seu cumprimento, permanece a resistência e o solipsismo de alguns magistrados, o que se verifica nas Reclamações sobre a matéria posteriores ao entendimento firmado nos acórdãos das referidas ações de controle concentrado de constitucionalidade.

A discricionariedade judicial em apreço reflete a histórica cultura jurídica de primazia da igualdade formal, prestigiando uma fictícia isonomia entre as partes, o que responsabiliza a própria vítima em situação de vulnerabilidade pela gestão e solução do conflito, alegando-se atenção à sua já subtraída autonomia. Olvida-se que, exatamente pela omissão das instituições estatais que possuem deveres de proteção, não lhe são dadas condições para o resgate de sua autonomia real e para a ruptura com o ciclo de violência, chegando-se aos desfechos fatais.

\section{REFERÊNCIAS}

ALMEIDA, Suely Souza de. Femicídio: algemas (in)visíveis do público-privado. Rio de Janeiro: Editora Revinter, 1998.

impotência. Rio de Janeiro: Revinter, 1995. 
AZEVEDO, Rodrigo Ghiringhelli de; CRAIDY, Mariana. Conflitos de Gênero no Judiciário: a aplicação da Lei 11.340/06 pelo Juizado de Violência Doméstica e Familiar de Porto Alegre/RS. In: Azevedo, Rodrigo Ghiringhelli de (org). Relações de Gênero e Sistema Penal: Violência e Conflitualidade nos Juizados de Violência Doméstica e Familiar contra a Mulher. Porto Alegre: EDIPUCRS, 2011.

BARSTED, Leila de Andrade Linhares. A resposta legislativa à violência contra as mulheres no Brasil. In: ALMEIDA, Suely Souza de. (Org.). Violência de gênero e políticas públicas. Rio de Janeiro: Editora UFRJ, 2007.

BOURDIEU, Pierre. A dominação masculina. Rio de Janeiro: Bertrand Brasil, 1999.

BRASIL Lei $n^{0}$ 9.099, de 26 de setembro de 1995. Dispõe sobre os Juizados Especiais Cíveis e Criminais e dá outras providências. Disponível em: <http://www.planalto.gov.br/ccivil_03/Leis/L9099.htm>. Acesso em: 03 de agosto de 2015.

Constituição da República Federativa do Brasil de 1988.

Disponível em: <http://www.planalto.gov.br/ccivil_03/Constituicao/Constituicao.htm>. Acesso em: 03 de agosto de 2015.

Lei $\mathrm{n}^{\mathbf{0}}$ 11.340, de 7 de agosto de 2006. Cria mecanismos para coibir a violência doméstica e familiar contra a mulher, nos termos do $§ 8$ o do art. 226 da Constituição Federal, da Convenção sobre a Eliminação de Todas as Formas de

Discriminação contra as Mulheres e da Convenção Interamericana para Prevenir, Punir e Erradicar a Violência contra a Mulher; dispõe sobre a criação dos Juizados de Violência Doméstica e Familiar contra a Mulher; altera o Código de Processo Penal, o Código Penal e a Lei de Execução Penal; e dá outras providências. Disponível em:

<http://www.planalto.gov.br/CCIVIL/_Ato20042006/2006/Lei/L11340.htm>. Acesso em 3 de agosto de 2015.

Supremo Tribunal Federal. Acórdão da Ação Declaratória de Constitucionalidade n⿳ 19/DF. Relator: Ministro MARCO AURÉLIO, Plenário, julgado em 09-02-2012, DJe 29-04-2014.

- Supremo Tribunal Federal. Acórdão da Ação Direta de Inconstitucionalidade $n^{0}$ 4424/DF. Relator: Ministro MARCO AURÉLIO, Plenário, julgado em 09-02-2012, DJe 01-08-2014.

Supremo Tribunal Federal. Decisão Monocrática do Recurso Extraordinário $\mathbf{n}^{\circ} \mathbf{8 2 6 7 6 0 / D F}$. Relator: Ministro TEORI ZAVASCKI, julgado em 01-082014, DJe 08-08-2014.

BUTLER, Judith. Problemas de Gênero: Feminismo e subversão da identidade. Trad. Renato Aguiar. 5. ed. Rio de Janeiro: Civilização Brasileira, 2013.

CAMPOS, Carmen Hein; CARVALHO, Salo de. Violência doméstica e Juizados Especiais Criminais: análise a partir do feminismo e do garantismo. In: Revista Estudos Feministas, Florianópolis: UFSC, v. 14, n.2, p. 409-422. 2005. 
CEDAW. Relatório nacional brasileiro: Convenção sobre a eliminação de todas as formas de discriminação contra a mulher, Protocolo facultativo. PIOVESAN, Flávia; PIMENTEL, Sílvia (coord.). Brasília: Ministério das Relações Exteriores, Ministério da Justiça, Secretaria de Estado dos Direitos da Mulher, 2002.

COMPROMISSO E ATITUDE. Central de Atendimento à Mulher - Ligue 180.

Disponível em: <http://www.compromissoeatitude.org.br/dados-nacionais-sobre-violenciacontra-a-mulher>. Acesso em: 20 de dezembro de 2015.

DIAS, Maria Berenice. A Lei Maria da Penha na Justiça: A efetividade da Lei 11.340/2006 de combate à violência doméstica e familiar contra a mulher. São Paulo: Revista dos Tribunais, 2007.

FOUCAULT, Michel. Microfísica do poder. Trad. Roberto Machado. 25.ed. São Paulo: Graal, 2012.

HABERLE, Peter. A dignidade humana como fundamento da comunidade estatal. In: SARLET, Ingo Wolfgang. (org.). Dimensões da dignidade: ensaios de filosofia do direito e direito constitucional. Porto Alegre: Livraria do Advogado Editora, 2005.

HERMANN, Jaqueline; BARSTED, Leila de Andrade Linhares. O Judiciário e as violências contra a mulher: a ordem legal e a (des)ordem familiar. Cadernos Cepia, Rio de Janeiro, n.2, 1995.

LUIZ, Fernando Vieira. Teoria da decisão judicial: dos paradigmas de Ricardo Lorenzetti à resposta adequada à Constituição de Lênio Streck. Porto Alegre: Livraria do Advogado Editora, 2013.

PIOVESAN, Flávia. Temas de Direitos Humanos. São Paulo: Max Limonad, 2003.

ROCHA, Lourdes de Maria Leitão Nunes. Casas-abrigo no enfrentamento da violência de gênero. São Paulo: Veras Editora, 2007.

Violência de gênero e o cumprimento da lei no Brasil: a atuação do campo jurídico. In: ALMEIDA, Suely Souza de. (Org.). Violência de gênero e políticas públicas. Rio de Janeiro: Editora UFRJ, 2007a.

. Violência de Gênero, Violência Doméstica e Intrafamiliar e

Direitos das Mulheres no Brasil. In: Gonçalves, Cláudia Maria da Costa (org.). Direitos Humanos: Direitos de quem? Curitiba: Juruá, 2012.

SARLET, Ingo Wolfgang. A Eficácia dos Direitos Fundamentais: Uma Teoria Geral dos Direitos Fundamentais na Perspectiva Constitucional. 10.ed. Porto Alegre: Livraria do Advogado Editora, 2009.

SENADO FEDERAL. Violência Doméstica e Familiar contra a mulher. Disponível em : $<$ http://www.senado.gov.br/senado/datasenado/pdf/datasenado/DataSenado-Pesquisa- 
Violencia_Domestica_e_familiar_contra_a_mulher-08-2015.pdf $>$. Acesso em: 12 de agosto de 2015.

STRECK, Lênio Luiz. O que é isto - decido conforme minha consciência? 4.ed. Porto Alegre: Livraria do Advogado Editora, 2013.

WAISELFISZ, Julio Jacobo. Mapa da violência 2015: homicídio de mulheres no Brasil. Disponível em: <http://www.mapadaviolencia.org.br>. Acesso em: 20 de dezembro de 2015. 